\title{
Effects of temperature and gadid predation on snow crab recruitment: comparisons between the Bering Sea and Atlantic Canada
}

\author{
Laurinda A. Marcello ${ }^{1, *}$, Franz J. Mueter ${ }^{1}$, Earl G. Dawe ${ }^{2}$, Mikio Moriyasu ${ }^{3}$ \\ ${ }^{1}$ School of Fisheries and Ocean Sciences, University of Alaska Fairbanks, Juneau, Alaska 99801, USA \\ ${ }^{2}$ Northwest Atlantic Fisheries Centre, Fisheries and Oceans Canada, St John's, Newfoundland and \\ Labrador A1C 5X1, Canada \\ ${ }^{3}$ Gulf Fisheries Centre, Fisheries and Oceans Canada, Moncton, New Brunswick E1C 9B6, Canada
}

\begin{abstract}
Snow crabs Chionoecetes opilio are found in many subarctic ecosystems, where they are important components of marine food webs and support large commercial fisheries. Snow crab abundance is highly variable, but the causes of large changes in year-class strength are poorly known. We used a regression approach to examine the effects of snow crab spawning stock biomass, bottom water temperature, cold area or sea ice extent, and predation by Pacific cod Gadus macrocephalus or Atlantic cod G. morhua on snow crab recruitment in each of 3 ecosystems: the eastern Bering Sea, the Newfoundland-Labrador Shelf, and the southern Gulf of St. Lawrence. Comparing results across systems showed that cold ocean conditions during early life history were associated with increased snow crab recruitment or recruitment indices in all 3 ecosystems. However, we found no consistent evidence that spawning stock or gadid biomasses were significantly related to subsequent snow crab recruitment. Our results underscore the value of comparing multiple ecosystems and demonstrate the importance of ocean conditions in driving variability in snow crab populations.
\end{abstract}

KEY WORDS: Snow crab - Recruitment - Environment - Predation - Spawning stock biomass · Eastern Bering Sea $\cdot$ Newfoundland-Labrador Shelf · Southern Gulf of St. Lawrence

\section{INTRODUCTION}

Snow crabs Chionoecetes opilio are found in shelf and slope areas of several subarctic ecosystems in the Pacific and Atlantic Oceans (Sainte-Marie et al. 2008). They serve an important trophic role in these systems and support large male-only commercial fisheries. Rational management of these important resources requires a sound understanding of factors that affect their population dynamics.

Snow crab abundance can be highly variable and is believed to be driven largely by changes in the strength of incoming year classes (Zheng \& Kruse
2006). However, the drivers of fluctuations in production and survival of these early life history stages, before snow crab are first detected by survey gear, are poorly known. Spawning stock biomass influences production levels (Zheng \& Kruse 2003, 2006) but relationships with recruitment are unclear because of large variations in spawner to recruit survival. Cannibalism on newly settled juveniles by previously settled year classes may influence survival and contribute to cyclical recruitment (Sainte-Marie et al. 1996, Sainte-Marie \& Lafrance 2002). Bottomup effects from ocean-climate variability may affect recruitment and abundance in snow crab (Zheng \& 
Kruse 2006, Dawe et al. 2008, Boudreau et al. 2011). Snow crab generally inhabit regions of very cold water (Sainte-Marie et al. 2008), especially during early benthic and juvenile stages (Dawe \& Colbourne 2002, Orensanz et al. 2004), and are energetically confined to cold areas (Foyle et al. 1989). Hence, their distribution and abundance, as well as survival, may be limited by the spatial extent of cold bottom waters. Alternatively, snow crab population dynamics and subarctic ecosystem structure may also be regulated by predation pressure from upper trophic levels ('top-down' effects) (Frank et al. 2005, Link et al. 2009). In particular, recent increases in snow crab biomass in Atlantic Canada have been attributed to declines in biomass of groundfish predators (Frank et al. 2005). Changes in snow crab recruitment and abundance may be influenced by the above factors or others, such as disease (Morado et al. 2010, Mullowney et al. 2011) and resource competition.

By comparing snow crab dynamics across similar ecosystems, we may be able to gain a better understanding of what drives ecosystem processes (Murawski et al. 2010). Subarctic ecosystems in both the North Pacific and North Atlantic Oceans share many commonalities including the presence of commercially important snow crab and large gadid predators. This study compares population dynamics of snow crab in the eastern Bering Sea (EBS), the southern Gulf of St. Lawrence (SGSL), and 2 regions in the Newfoundland-Labrador Shelf (NL) ecosystem to address the following question: Is snow crab abundance governed by analogous factors across subarctic ecosystems or do snow crab in each ecosystem respond to important drivers in different ways?

Specifically, we investigate how the spawning stock biomass, the environment (water temperature or cold area extent), and the biomass of gadoid fishes impact snow crab recruitment or recruitment indices. Three hypotheses were tested for each of 3 ecosystems: $\left(H_{\mathrm{A} 1}\right)$ snow crab recruitment shows an increasing or compensatory (e.g. asymptotic or dome-shaped) response to spawning stock biomass (density dependence); $\left(H_{\mathrm{A} 2}\right)$ colder conditions, represented by lower temperatures, a larger spatial extent of cold bottom temperatures, or more extensive ice cover will result in increased recruitment; and $\left(H_{\mathrm{A} 3}\right)$ increased biomass of potential predators will be associated with decreased snow crab recruitment. These hypotheses were tested in a statistical modeling framework relating estimates or indices of snow crab recruitment to variability in predation, spawning stock biomass, and the environment.

\section{MATERIALS AND METHODS}

\section{Study areas}

We examined snow crab dynamics in 3 subarctic ecosystems that are characterized by a high degree of seasonality in ice cover and sunlight and by large influxes of freshwater (Hunt \& Drinkwater 2007). Snow crab generally inhabit shelf or slope areas and are typically associated with a cold pool of water (Dawe \& Colbourne 2002, Sainte-Marie et al. 2008). Relationships between snow crab recruitment or recruitment indices and potential explanatory variables were modeled for 4 regions in 3 large marine ecosystems: (1) EBS, (2) SGSL, Northwest Atlantic Fisheries Organization (NAFO) Division 4T, and 2 regions in NL, (3) NAFO Division 3K (NAFO 3K) and (4) NAFO Division 3L (NAFO 3L) (Fig. 1). The 2 NL regions were modeled separately because snow crab abundance trends and thermal regimes differed between the regions. Data are aggregated at the division level before being combined for the NL system as a whole (DFO 2010); area NAFO 3K corresponds to the relatively deep and warm northeast Newfoundland Shelf, while NAFO 3L is over the shallow colder Grand Bank.
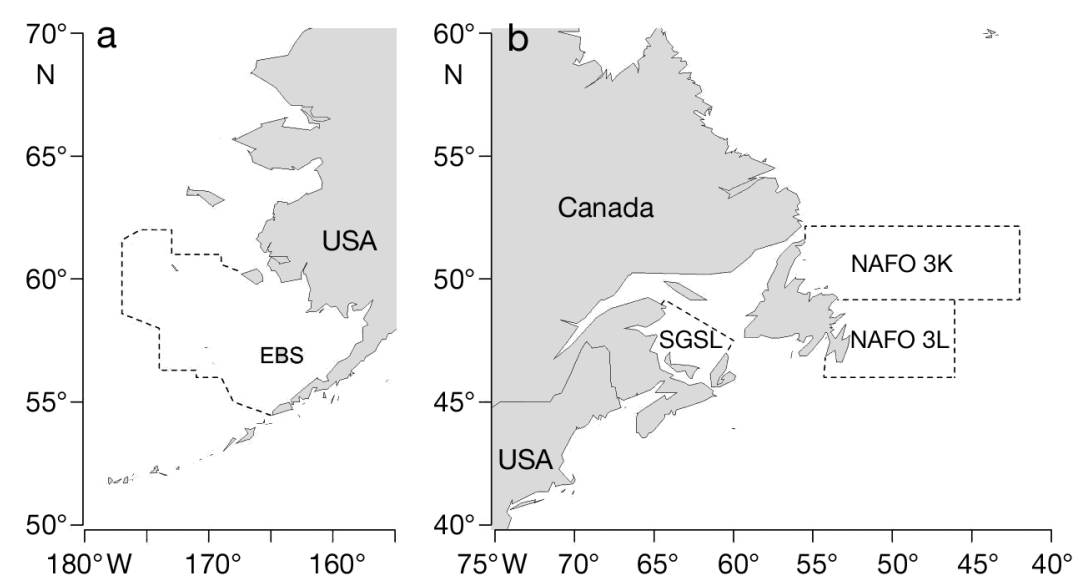

Fig. 1. Study regions used to model the effects of spawners, the environment, and predation by gadoid fishes on snow crab recruitment in (a) the eastern Bering Sea (EBS) and (b) the Northwest Atlantic Fisheries Organization (NAFO) Division 4T in the Gulf of St. Lawrence (SGSL), and NAFO Divisions 3K (NAFO 3K) and 3L (NAFO 3L) off the Newfoundland-Labrador Shelf 


\section{Data}

\section{Snow crab data}

For the EBS and SGSL, time series of estimated recruitment were used as the primary response variables. Hereafter, we use the general term 'recruitment' to refer to the estimated or modeled abundance of a specific size-class, which is smaller than the smallest age group recruiting to the fishery. For the EBS, recruits become vulnerable to survey gear over the size range of 30 to $60 \mathrm{~mm}$ carapace width (Orensanz et al. 2004). We used the number of individuals, in millions, between 25 and $40 \mathrm{~mm}$ carapace width for the years 1984 to 2007 as estimated from a statistical, size-structured model based on survey and fishery data (Turnock \& Rugolo 2010). This represents the best available index of recruitment, although it does not fully account for small crab occurring to the north of the standard survey area. Crabs of this size class are thought to be 4 yr from hatching and $5 \mathrm{yr}$ from fertilization (Turnock \& Rugolo 2010). Recruitment of instar VIII snow crab in the SGSL was modeled based on survey data from 1989 to 2009 (DFO 2010) and indexed on a scale from 0 to 100 for this study. The SGSL trawl survey was conducted during fall in Fishing Area 12, which is the largest fishing area in the SGSL. No survey was conducted in 1996 and a model-derived value was substituted for this year (Hébert et al. 1997). SGSL instar VIII snow crab are 30.7 to $34.5 \mathrm{~mm}$ carapace width and have been estimated to be 4.3 to 5 yr from hatching (Sainte-Marie et al. 1995, Hébert et al. 2002). Although the SGSL recruits cover a narrower size range than in the EBS, the 2 size classes correspond to approximately the same age range. Snow crab can reach sexual maturity over several different instars, beginning from 35 (Ernst et al. 2005) to $40 \mathrm{~mm}$ carapace width (Hébert et al. 2002).

For the 2 NL regions, available trawl survey time series were too short for modeling purposes. However, fluctuations in the exploitable biomass and abundance are largely dependent on the strength of incoming recruitment to the fishery (males larger than $94 \mathrm{~mm}$ carapace width) and should reflect the abundance of the youngest year classes entering the fishery (approximately age 10). Therefore, we used catch-per-unit-effort (CPUE in $\mathrm{kg} \mathrm{trap}^{-1}$ for snow crab >94 mm carapace width) as a crude recruitment index in these regions (1977 to 2008 for NAFO 3K, 1974 to 2008 for NAFO 3L). To validate this approach, we compared fishery CPUE to trawl survey abundance indices for various limited size groups of new-shelled crabs. Convincing direct relationships were found between the CPUE and trawl survey abundance indices at appropriate lags for both NL regions (E. Dawe unpubl. data). Hereafter, we refer to these CPUE series as 'recruitment index.'

The reproductive potential of snow crab influences larval production and this may be reflected in variations in recruitment. To address our first hypothesis linking spawner biomass to later recruitment, we used proxies for spawning stock biomass as measures of reproductive potential (Fig. 2). In the EBS we used an estimate of total mature snow crab biomass (morphometrically mature males plus mature females) based on survey size composition and maturity at size estimated in the stock assessment (Turnock \& Rugolo 2010). In all other areas (SGSL, NAFO 3K and 3L), CPUE of male snow crab $95 \mathrm{~mm}$ carapace width or larger was used as a proxy for spawning stock biomass, hereafter called 'spawning stock biomass index'. These measures were incorporated at appropriate lags in regression models to assess potential impacts of spawner biomass on recruitment as described below.

\section{Environmental data}

To capture the potential effects of ocean climate variability on snow crab recruitment we selected bottom temperatures and cold area extent (measured either as the extent of the cold layer of water that forms as a result of winter cooling and ice cover or as the spatial extent of the sea ice itself) as environmental variables for modeling (Fig. 2).

For the EBS, a long-term proxy for bottom temperature was constructed using the NOAA extended reconstructed sea surface temperature data series (Smith et al. 2008, NOAA 2011). The proxy uses sea surface temperatures averaged over the spring and late summer periods (March, April, May, and August), when water column temperatures were most strongly correlated with average bottom temperatures over the shelf (Pearson's product moment correlation $\mathrm{r}=$ 0.88 ) due to vertical mixing. Bottom temperatures in the SGSL were measured annually at Magdalen Shallows during September (Chassé \& Pettipas 2010). For both NL areas (NAFO 3K and NAFO 3L), a time series of annual mean bottom temperatures at Stn 27, an oceanographic monitoring station located $7 \mathrm{~km}$ from St. John's Harbour (Newfoundland), was selected as a measure of temperature variability in these regions (Dawe et al. 2008). 


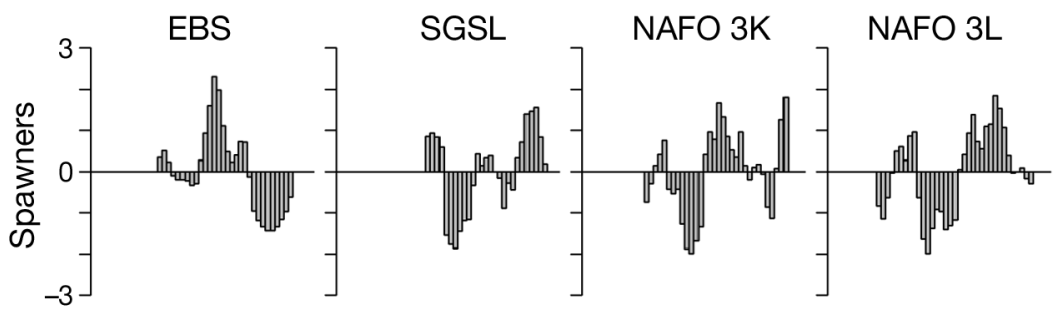

45 to $55^{\circ} \mathrm{N}$ on the NewfoundlandLabrador Shelf (Dawe et al. 2008) was used to represent the spatial extent of cold water.

\section{Predators}
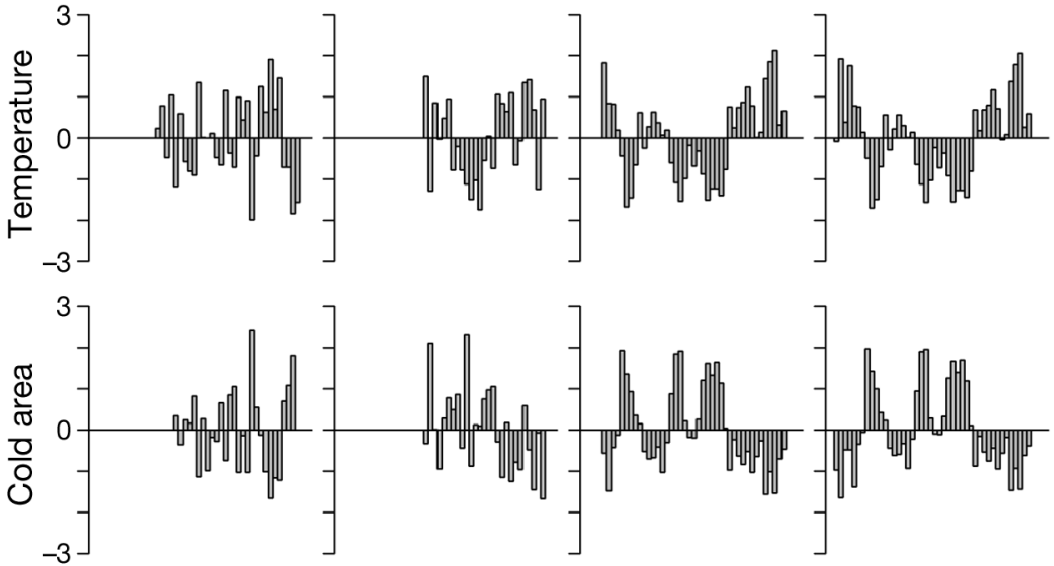

To examine the potential effects of key predators on snow crab recruitment in each system, and to address hypothesis $H_{\mathrm{A} 3}$, suitable estimates of predator biomass were compiled (Fig. 2). Although there are many predators of snow crab, this study focused on predation by gadoid fishes. Walleye pollock Theragra chalcogramma dominate gadid biomass in the EBS, but were not included here because snow crab make up a very small proportion of their diet (Aydin et al. 2007). The major gadid predator on snow crab in the EBS is Pacific cod Gadus macrocephalus (Livingston 1989), and we used a model-based estimate of the total biomass of Pacific cod age 0+ from the 2007 stock assessment model (Thompson et al. 2010) to quantify potential gadid predation in this system. In both Atlantic Ocean ecosystems, Atlantic cod Gadus morhua has historically been a predator of snow crab. In the SGSL, Atlantic cod age 3+ biomass estimates from the 2009 stock assessment model (Swain et al. 2009) were used to examine predation effects. In NL regions NAFO $3 \mathrm{~K}$ and $3 \mathrm{~L}$, estimates

Seasonal ice cover is an important feature of all the study areas examined here. It determines the spatial extent of the cold pool in the EBS and is related to the area of the cold intermediate layer in Atlantic Canada. Because the spatial extent of these cold waters has important effects on the distribution of snow crab (Dionne et al. 2003, Orensanz et al. 2004), we examined the influence of cold area extent in each region. For the EBS, cold area extent represents the fraction of the National Marine Fisheries Service summer bottom trawl survey area with water less than $2^{\circ} \mathrm{C}$ (F. Mueter unpubl. data). The SGSL cold area variable represents the area $\left(\mathrm{km}^{2}\right)$ of Magdalen Shallows covered by -1 to $3^{\circ} \mathrm{C}$ bottom water during September (Chassé \& Pettipas 2010). For NAFO 3K and NAFO 3L, the annual ice cover area $\left(\mathrm{km}^{2}\right)$ from of total Atlantic cod biomass from autumn surveys (conducted through 2007) were used.

\section{Analytical approach}

A general regression approach was used to examine the effects of snow crab spawning stock biomass, environmental variability, and predation on snow crab recruitment in each ecosystem. The basic modeling structure was as follows:

$$
\begin{gathered}
y_{t}=\beta_{0}+\beta_{1} \text { spawners }_{t-k 1}+\beta_{2} \text { environment }_{t-k 2}+ \\
\beta_{3} \text { predator }_{t-k 3}+\varepsilon_{t}
\end{gathered}
$$

where $y_{t}$ represents snow crab recruitment (or recruitment index) in year $t, \beta$ s are regression coeffi- 
cients, $k 1, k 2$, and $k 3$ represent time lags, and the errors $\varepsilon_{\mathrm{t}}$ are assumed to be either independent and normally distributed with mean zero and variance $\sigma^{2}$ or first order autocorrelated $\left(\varepsilon_{t}=\phi \varepsilon_{t-1}+v_{t}\right)$ with autoregressive coefficient $\phi$ and innovations $v_{t}$ that are independent and normally distributed.

Recruitment data often have a skewed distribution and may require a transformation to achieve normality in model residuals. A range of Box-Cox transformations (Box \& Cox 1964) were explored to identify the best power transformation for each response variable $\left(y_{t}\right)$ to achieve approximate normality of the residuals. Likelihood profiles indicated that a $\log$ transformation was the best possible transformation for the EBS and SGSL recruitment series, while no transformation was necessary for the NAFO $3 \mathrm{~K}$ and NAFO 3L recruitment indices.

Spawning stock biomass affects larval production, while both predation and the environment may influence survival. Each of these factors would be expected to alter population abundances several years prior to recruitment and the effects may extend over multiple years, necessitating the use of lags and moving averages for the explanatory variables. Available diet studies suggest that early life history stages of snow crab are particularly vulnerable to predation (Livingston 1989, Chabot et al. 2008). For example, in the Gulf of St. Lawrence, 4 size groups of crab were susceptible to Atlantic cod predation (Chabot et al. 2008). These sizes roughly correspond to ages 1 to $4 \mathrm{yr}$ (Hébert et al. 2002), although there can be some variability in growth to each size class. Similarly, environmental conditions including temperature can affect larval and juvenile stages of snow crab by influencing development rate (Moriyasu \& Lanteigne 1998), hatch timing (Webb et al. 2007), growth rate, and molt frequency (Orensanz et al. 2007), as well as energy budgets (Foyle et al. 1989). Since effects may range over several life stages and because snow crab cannot be aged reliably, 3 or 4 yr moving averages were applied to time series of both predators and environmental variables to capture their potential effects on multiple age classes of snow crab. Likewise, moving averages were applied to spawning stock biomass series because the time period between fertilization and growth to the recruitment size class varies. The averaged variables were then lagged by $k$ years relative to the response in Year $t$ to correspond to the approximate period when the effect is presumed to occur (Year $t-k)$. For example, the recruitment of EBS snow crab is most likely to be influenced by the parental stock 4 to 6 yr prior (Table 1); hence, recruits in 1995 were modeled as a function of the spawning stock bio-
Table 1. Explanatory variables used in this study, by region, with lags considered for each variable. Lags denote the time range (in yr) prior to the year when snow crab recruitment (eastern Bering Sea, EBS; southern Gulf of St. Lawrence, SGSL) or recruitment indices (in Newfoundland-Labrador NAFO Divisions 3K and 3L) were measured. Ranges include only those years during which explanatory variables may reasonably be expected to affect snow crab subsequent recruitment. Spawners: snow crab spawners

\begin{tabular}{|lcc|}
\hline Region & Explanatory variable & Lags (yr) \\
\hline EBS & Spawners & $4-6$ \\
& Temperature & $2-4$ \\
& Cold area cover & $2-4$ \\
SGSL & Pacific cod & $2-4$ \\
& Spawners & $4-6$ \\
& Temperature & $3-5$ \\
& Cold area cover & $3-5$ \\
NAFO 3K & Atlantic cod & $2-4$ \\
& Spawners & $9-11$ \\
& Temperature & $7-9$ \\
& Sea ice extent & $7-9$ \\
NAFO 3L & Atlantic cod & $5-8$ \\
& Spawners & $9-11$ \\
& Temperature & $7-9$ \\
& Sea ice extent & $7-9$ \\
& Atlantic cod & $7-10$ \\
\hline
\end{tabular}

mass averaged over 1989 to 1991. In some cases, several biologically reasonable lags were considered, such as in NL regions NAFO 3K and NAFO 3L, where the recruitment index was based on snow crab of commercial size (>94 mm carapace width). In those areas it was reasonable to consider predation effects over several lags (ranging from 5-8 yr to $7-10 \mathrm{yr}$ prior) due to uncertainty and variability in the age at which snow crab reach commercial size. When multiple lags were considered, the lag that resulted in the lowest $p$-value in a simple linear regression between the recruitment index or the log of recruits and each explanatory variable was selected for use in regression models. The lags and moving averages used for all variables in each model are listed in Table 1.

For some ecosystems, the length of overlapping time series was limited once the predator and/or spawner series were lagged appropriately. For these systems both 'short models' including all variables and 'long' models including fewer variables were tested. For example, the Atlantic cod series in NAFO $3 \mathrm{~L}$ overlapped with the response variable by only $16 \mathrm{yr}$, whereas the spawner and environmental variables were available over longer time periods $(\mathrm{n}=24$ and $\mathrm{n}=35 \mathrm{yr}$, respectively). Results from analyses using the short and long series were then compared for consistency. We considered the results to be con- 
sistent when the sign of all explanatory variables remained unchanged regardless of whether the short or the long series were used.

A species may exhibit non-linear, non-additive, or threshold responses to external pressures (Cury et al. 1995, Ciannelli et al. 2007, 2008). To explore potential non-linearities and thresholds we fit exploratory generalized additive models (GAMs) to the data using a cross-validation approach before constructing a corresponding linear model for further analysis. To avoid over-fitting we limited parameter smoothness by constraining the estimated degrees of freedom (EDF) for any variable to 3, corresponding to a biologically realistic set of possible responses (approximately linear, asymptotic, or dome-shaped). Partial fits for each explanatory variable and the estimated degrees of freedom were examined, and a squared term was included in the full linear model for any variable with EDF $>1.5$. No higher-order polynomial terms were considered as they were not deemed biologically reasonable.

For each ecosystem, both a temperature variable and cold area extent (or sea ice extent) were available for modeling. However, bottom temperatures were strongly correlated with cold area cover and/or sea ice extent in each system (multicollinearity). Therefore, the effects of these variables were modeled separately and compared for consistency. For each system, the initial full linear model included one environmental variable, a cod predator, and spawning stock biomass. We tested for interactions among variables in each full model, and because we found no significant interactions, we did not consider interactions further. We compared the full model with all 3 variables to reduced models with 1 or 2 variables using the small-sample Akaike Information Criterion (AICc). The model with the smallest AICc was selected as the final model when the difference between AIC values, $\triangle \mathrm{AICC}$, was $>4$ (Burnham \& Anderson 2002). If differences in AICc were $<4$, the most parsimonious model was selected as the final model.

Residuals from both the initial (full) model and from the final (AICc-best) model were examined for normality, heteroscedasticity, and autocorrelation. When significant autocorrelation $(p<0.05)$ was present in residuals from the full model according to a Durbin-Watson (DW) test, all model comparisons were based on generalized least squares fits that included a first-order auto-regressive error term. The overall significance of the final (AICc-best) model was tested using the likelihood ratio test (LRT) for generalized least squares models or F-test for linear models without autocorrelation.

Program R version 2.9 (R Development Core Team 2011) was used for all analyses and a level of $\alpha=0.05$ was chosen to assess significance.

\section{RESULTS}

In the EBS, cold temperatures were related to increased recruitment, consistent with our hypothesis, but results did not support a predation effect (Tables $2 \& 3$ ). The final model included temperature

Table 2. Regression coefficients with p-values (in parentheses) for final model fits of snow crab recruitment or fishery recruitment indices in 4 regions (eastern Bering Sea, EBS; southern Gulf of St. Lawrence, SGSL; NAFO Division 3K, NAFO 3K; and NAFO Division 3L, NAFO 3L). Coefficients denote intercept $\left(\beta_{0}\right)$ and estimated effects of spawning stock biomass $\left(\beta_{1}\right)$, temperature or sea ice extent $\left(\beta_{2}\right)$, predator biomass $\left(\beta_{3}\right)$, and a first-order autoregressive parameter $(\varphi)$, if significant. Predators are Pacific cod in the EBS and Atlantic cod elsewhere

\begin{tabular}{|c|c|c|c|c|c|c|}
\hline Region & $\begin{array}{c}\text { Environmental } \\
\text { variable }\end{array}$ & $\beta_{0}$ & $\beta_{1}$ & $\beta_{2}$ & $\beta_{3}$ & $\varphi$ \\
\hline EBS & Temperature & $\begin{array}{c}16.50 \\
(<0.001)\end{array}$ & $\begin{array}{c}-5.38 \times 10^{-3} \\
(0.032)\end{array}$ & $\begin{array}{l}-2.12 \\
(0.006)\end{array}$ & & 0.66 \\
\hline SGSL & Temperature & $\begin{array}{c}5.12 \\
(<0.001)\end{array}$ & & $\begin{array}{l}-2.85 \\
(0.020)\end{array}$ & & 0.73 \\
\hline NAFO 3K & Sea ice extent & $\begin{array}{c}6.80 \\
(0.035)\end{array}$ & & $\begin{array}{c}4.72 \\
(0.034)\end{array}$ & & 0.91 \\
\hline NAFO $3 L^{a}$ & $\begin{array}{l}\text { Temperature } \\
\text { Sea ice extent }\end{array}$ & $\begin{array}{c}20.27 \\
(<0.001) \\
20.91 \\
(<0.001)\end{array}$ & $\begin{array}{c}-0.65 \\
(<0.001) \\
-0.70 \\
(<0.001)\end{array}$ & $\begin{array}{c}-2.73 \\
(0.008) \\
2.98 \\
(0.011)\end{array}$ & $\begin{array}{c}-9.63 \times 10^{-3} \\
(0.001) \\
-9.63 \times 10^{-3} \\
(0.001)\end{array}$ & \\
\hline
\end{tabular}


Table 3. Summary of estimated effects of snow crab spawning stock biomass, the environment, and predation by cod on snow crab recruitment. For the eastern Bering Sea (EBS) and southern Gulf of St. Lawrence (SGSL) the response variable was the log of the estimated number of recruits at a small size. In the 2 Newfoundland-Labrador systems (NAFO 3K and NAFO 3L), a fishery recruitment index was the response variable. Predators are Pacific cod (EBS) and Atlantic cod (SGSL, NAFO 3K, NAFO 3L).Variables that were significant to the final models are shown in plus or minus signs, while those that are not significant are indicated by NS

\begin{tabular}{lcccc|}
\hline & EBS & SGSL & NAFO 3K & NAFO 3L \\
\hline Spawners & - & NS & NS & $-^{\mathrm{a}}$ \\
Temperature & - & - & NS & - \\
Cold area cover/ & NS & NS & + & + \\
sea ice extent & & & & - \\
Predators & NS & NS & $+/{ }^{\mathrm{b}}$ & - \\
a Spawners were negatively related to the recruitment \\
index in both short and long models; however, they \\
were only significant in the short model \\
besults from models including and excluding Atlantic \\
cod were not consistent \\
\hline
\end{tabular}

and spawning stock biomass; both variables were negatively and linearly related to the log of recruitment $(\mathrm{n}=24 \mathrm{yr}, \mathrm{LRT}=20.75, \mathrm{p}<0.001)$ and explained approximately $38 \%$ of the variability in recruitment (Fig. 3a). The model included a first-order autoregressive term $(\varphi=0.66)$ to account for significant autocorrelation in the residuals (DW $=0.93, \mathrm{p}<0.001$, Fig. 4a). When replacing temperature with the cold area extent ( $\mathrm{n}=22 \mathrm{yr}$ ) in the full model, its estimated effect was not significant $(t=1.45, \mathrm{p}=0.164)$, but its sign was consistent with a positive effect of cold conditions on recruitment.

In the SGSL we found a negative linear relationship between temperature and the log of recruitment, but neither a predation nor a spawner effect ( $\mathrm{n}=21 \mathrm{yr}$, Tables 2 \& 3). The final model included the temperature variable $(\mathrm{LRT}=20.81, \mathrm{p}<0.001$, Table 2 ) and explained about $41 \%$ of the recruitment variability (Fig. 3b). A first-order auto-regressive term $(\varphi=$ $0.73)$ was included in the model to account for residual autocorrelation (DW $=0.77, \mathrm{p}<0.001$, Fig. 4b). The full model for SGSL based on cold area extent rather than temperature was not significant overall (LRT $=4.66, \mathrm{p}=0.32$ ) and contained no significant variables $(p>0.05)$. Therefore, models with cold area extent were dropped from further consideration.

In the NL area, NAFO 3K sea ice extent was positively related to the snow crab recruitment index 7 to 9 yr later (Table 2), meaning sea ice conditions appear to affect snow crab at approximately 1 to 3 yr of age. There was no evidence of an effect of spawner stock biomass index or temperature on snow crab recruitment index and the relationships with Atlantic cod biomass were inconsistent (Table 3). Models for NAFO 3K that included the Atlantic cod series ( $\mathrm{n}=18 \mathrm{yr}$ ) differed substantially from those including just other variables $(n=21$ for spawners, $\mathrm{n}=32$ for temperature or ice area). Specifically, when Atlantic cod biomass was included in these models, the sign and significance of other coefficients changed drastically, most likely as a result of strong correlations between Atlantic cod and the other explanatory variables. Therefore, models including Atlantic cod were not considered further. Spawner stock biomass index was neither significant to the model with bottom temperature nor to the model using sea ice extent as a proxy for the cold area extent. Sea ice extent had a significant positive linear relationship with the snow crab recruitment index (Table 2), though it only explained a small proportion of overall variability (Fig. 3c, n =32 yr, LRT = 33.00, $\left.\mathrm{p}<0.001, \mathrm{R}^{2}=0.18\right)$. A first-order autoregressive term $(\varphi=0.91)$ was included to account for significant autocorrelation in the residuals (Fig. 4c, DW $=0.45, \mathrm{p}<0.001)$. When using bottom temperature as the environmental variable, none of the variables in the model were significant ( $p>0.05)$, but a negative temperature coefficient was consistent with the observed positive effect of extensive ice on the snow crab recruitment index.

In the other NL region, NAFO 3L, cold conditions and low predator biomasses were associated with a high recruitment index in following years. Spawner stock biomass index showed a negative association with the later recruitment index (Tables 2 \& 3). Models including Atlantic cod covered a shorter time period $(\mathrm{n}=16 \mathrm{yr})$ than those with spawner stock biomass index ( $\mathrm{n}=24 \mathrm{yr}$ ) or environmental conditions (temperature or sea ice extent, $\mathrm{n}=35$ ), but the sign of coefficients for spawner stock biomass index and temperature or sea ice extent remained consistent among models. Temperature or sea ice extent were significant in all models, though spawner stock biomass index was not significant in the longer $(n=24 \mathrm{yr}$ ) model. In the short models, spawner and predator biomasses were both negatively related to the subsequent snow crab recruitment index. Likewise, colder conditions were linked with a higher recruitment index. Both model fits explained about $90 \%$ of recruitment index variability over the $16 \mathrm{yr}$ modeled (temperature model: $F_{3,12}=45.62, \mathrm{p}<$ 



Fig. 3. Chionoecetes opilio. Time series of snow crab recruitment or recruitment indices (dots) with predicted values from best-fit models (lines) for (a) the eastern Bering Sea, (b) the southern Gulf of St. Lawrence, (c) Northwest Atlantic Fisheries Organization (NAFO) 3K, and (d) NAFO 3L (sea ice extent model). Best-fit models for each region are described in 'Results' and summarized in Table 2

0.001; sea ice extent model: Fig. $3 d, F_{3,12}=43.91, p$ $<0.001$ ), and there was no evidence of first-order autocorrelation in the residuals (temperature model: $\mathrm{DW}=2.05, \mathrm{p}=0.22$; sea ice-extent model: Fig. 4 d. $\mathrm{DW}=2.04, \mathrm{p}=0.22$ ).

Significant and pronounced autocorrelation was present in the recruitment or recruitment index residuals in the final models for 3 of 4 regions studied (EBS, SGSL, and NAFO 3K in the NL ecosystem), as was clearly evident in residual plots (Fig. 4). The first-order autoregressive structure of the generalized least squares models accounted for the observed serial correlation and ensured that significance tests and model comparisons are valid. However, clear cyclic patterns with several multi-year runs of alternating positive and negative residuals were evident in both the full models and in the AICc-best models. This suggests that models including environmental variables, predation and/or spawner effects, in combination with random measurement errors, do not fully account for the dynamics of these populations.

\section{DISCUSSION}

\section{Overview}

This study investigated the effects of 3 factors (spawning stock biomass, environmental conditions, and gadid biomass) on the strength of subsequent recruitment levels in snow crab and compared results across 3 subarctic ecosystems in the Northwest Atlantic and Northeast Pacific (Table 3). Our modeling results showed that ocean climate variability was the only factor that was consistently associated with recruitment in all ecosystems and regions. This strongly supports our hypothesis $\left(H_{\mathrm{A} 2}\right)$ that cold conditions during early life history stages promote subsequent snow crab recruitment (Fig. 5). In contrast, there was little support for a consistent effect of spawning stock or predator biomasses (hypotheses $H_{\mathrm{A} 1}$ or $H_{\mathrm{A} 3}$ ) on recruitment across systems. Spawning stock biomass was inversely related to recruitment in the EBS and NAFO 3L, possibly indicating a density-dependent effect on recruitment in those areas. Atlantic cod biomass was inversely related to recruitment, consistent with a predation effect, but only in NAFO 3L.

Our study shows that bottom-up processes related to ocean climate conditions appear to have a consistent influence on snow crab recruitment, while the importance of gadid biomass or spawning stock biomass is less clear. This study also highlights the value in comparing multiple ecosystems because con- 




Fig. 4. Model residuals through time for 4 geographic regions: (a) the eastern Bering Sea, (b) the southern Gulf of St. Lawrence, (c) Northwest Atlantic Fisheries Organization (NAFO) 3K, and (d) NAFO 3L (sea ice extent model). Residuals from several models have long runs of negative and positive residuals indicating a possible cyclical pattern in snow crab recruitment history, so it is unclear whether these indices reflect a common regulatory mechanism or if they represent different processes. Climate can be linked to snow crab reproduction and survival in several ways. For example, the hatch timing of larval crab is linked to temperature (Webb et al. 2007) and ice cover can affect stratification and larval feeding conditions in the spring (Orensanz et al. 2004). Recently settled juveniles are thought to be very stenothermic and have low mobility; they could represent the 'weakest link' in snow crab life history because they cannot easily escape unfavorable environmental conditions such as unfavorable temperatures (Dionne et al. 2003). Therefore, the area of cold water during summer may limit the amount of suitable habitat and hence the carrying capacity for early benthic stages (Dawe \& Colbourne 2002). In addition, temperature likely affects early survival directly by regulating the energy budget of individual crabs (Foyle et al. 1989). A laboratory experiment found that for mature male snow crab taken from the Scotian Shelf, total metabolic costs exceeded digestible energy intake in waters $7^{\circ} \mathrm{C}$ or higher and slightly exceeded digestible energy intake in 0 to $1^{\circ} \mathrm{C}$ water (Foyle et al. 1989). Therefore, snow crab may be excluded from warm waters based on energetic demands (Foyle et al. 1989). Conversely, it is known that cold conditions promote snow crab to terminally sistent responses across several systems greatly strengthen our conclusions about significant effects of temperature conditions on early life stages of snow crab.

\section{Environment, spawning stock biomass, and predation}

Our study suggests that colder conditions during early life are associated with better snow crab recruitment in all of the systems examined. Our indices of ocean climate are closely related, and we did not address mechanisms linking climate to snow crab life molt at a smaller size, which may reduce the proportion of commercially harvestable males in the total adult male population (Dawe et al. 2012b, this volume). Overall, the effects of temperature or cold area extent on early life stages seem to have a dominant effect on recruitment. However, in the present study, mean temperatures in each system varied within a narrow range (roughly $1.5^{\circ} \mathrm{C}$ ), and recruitment responses should not be extrapolated outside of the modeled temperature range. Although temperatures differed substantially among regions, relationships between recruitment and temperature were similar, suggesting that snow crab are adapted to local temperature conditions. Therefore, the effect of a given 

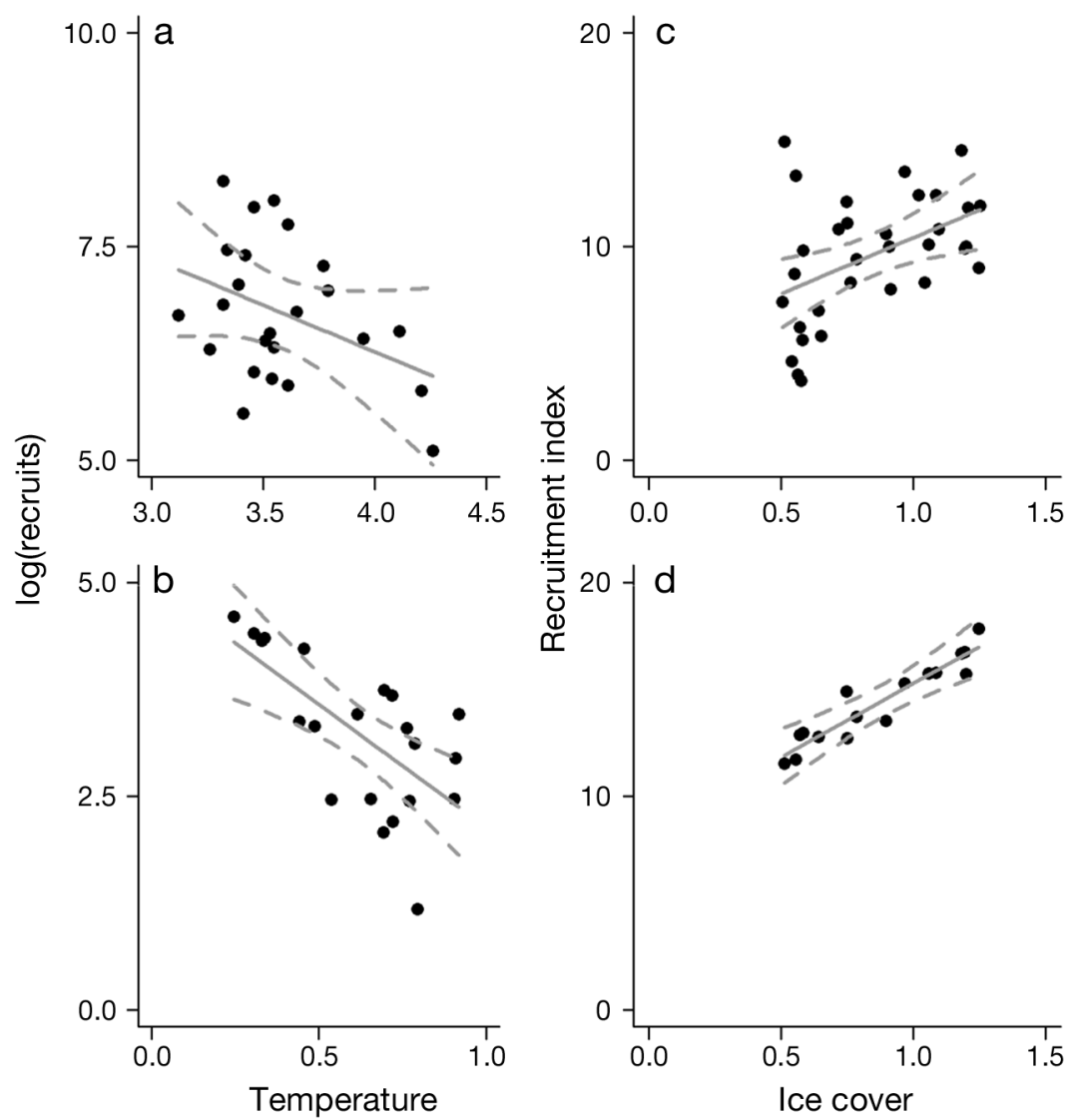

Fig. 5. Partial fits (solid lines) with $95 \%$ pointwise confidence intervals (dashed lines) illustrating the estimated effects of temperature and ice conditions on snow crab recruitment, while holding other variables constant at their mean values. Plots show the effect of temperature on recruitment in the (a) eastern Bering Sea and (b) southern Gulf of St. Lawrence and the effect of ice cover on recruitment indices in (c) Northwest Atlantic Fisheries Organization (NAFO) Division 3K and (d) NAFO Division 3L. Note that the axes differ among panels

temperature on recruitment must be evaluated relative to typical conditions for snow crab in each region.

For the cod predators considered in this study, we found a relationship with recruitment only in NAFO $3 \mathrm{~L}$ in the NL ecosystem. Considering the absence of any such effect in other regions, especially in the adjacent NAFO 3K area, our study found little evidence that cod biomass has exhibited top-down control on larval and juvenile snow crab since the late 1970s. In both the Newfoundland-Labrador Shelf (Lilly 2008) and in the Gulf of St. Lawrence (Ruppert et al. 2010), Atlantic cod populations have crashed from their historic levels and were at low abundances during most of the time period examined here. Consequently, there simply may be too few cod at the present time to exert significant population-level predation effects on young snow crab. The apparent predation effect in NAFO 3L may also result from opposing responses of snow crab and Atlantic cod to ocean climate variability, with snow crab increasing and cod decreasing during a prolonged cold period when cod was also excessively exploited (Dawe et al. 2008). However, our results do not imply that predation has no effect on snow crab recruitment. Previous studies indicate that predation may be important. For example, Livingston (1989) estimated that in the EBS, Pacific cod remove 27 to $57 \%$ of Age 1 snow crab from the population. Our results may differ for several reasons. First, the spatial scale of data may influence statistical analyses (Ciannelli et al. 2008, Windle et al. 2012, this volume) and hence our results. Biological data for this study represented large geographic regions and will fail to detect small-scale predatorprey interactions. Second, predation can have indirect effects on snow crab recruitment by limiting their geographic range. Climate conditions may affect predator-prey relationships by altering the spatial distributions of either species (Zheng \& Kruse 2006). Also, the EBS snow crab population has contracted northward in recent decades (Orensanz et al. 2004). The environmental ratchet hypothesis proposes that Pacific cod predation may help prevent snow crab from expanding and returning to more southern portions of the eastern Bering Sea shelf that provide favorable spawning habitat (Orensanz et al. 2004). Such spatial dynamics can lead to important predation effects that may not be evident in a relationship between time series of aggregated predator biomasses and prey recruitment. Finally, the diet of both cod species changes with age (Livingston 1989, Chabot et al. 2008), and the age classes of cod which are the most important consumers of snow crab may not be well-represented in aggregated biomass series.

A recent meta-analysis by Boudreau et al. (2011) looked for evidence of top-down and bottom-up controls on snow crab in the northwest Atlantic Ocean. Similar to our study, their results linked colder temperatures during the early years after settlement with 
higher subsequent snow crab abundances. In contrast to our study, they found statistical evidence of topdown control by Atlantic cod on snow crab 0 to $5 \mathrm{yr}$ later. For crab entering the fishery, these lags would correspond to snow crab approximately 29 to $97 \mathrm{~mm}$ carapace width or 3.3 to 8.7 yr of age. Their result including older crab is unexpected because cod generally consume snow crab that are younger than $4.5 \mathrm{yr}$ post-settlement (Chabot et al. 2008), and predation by cod on crabs in the NL ecosystem has been virtually non-existent for 2 decades due to very low abundance of large cod (Dawe et al. 2012a, this volume). However, at the longer lags, which correspond to predation on younger crab, the results of Boudreau et al. (2011) agree with expectations from available diet studies. Our predation results may differ from those found in Boudreau et al. (2011) in part due to methodological approaches. We selected suitable lags corresponding to the crab ages most vulnerable to predation a priori in order to minimize the chance of finding spurious relationships. Boudreau et al. (2011) considered a much larger range of lags ( $25 \mathrm{yr}$ ) since they were examining both the effects of crab on cod and of cod on crab. Furthermore, we used a regression approach that allowed us to consider the combined effects of multiple covariates, including spawning stock biomass, on crab recruitment at once. In contrast, Boudreau et al. (2011) considered pairwise full and partial correlation coefficients.

The lack of an obvious relationship between cod biomass and snow crab recruitment in our study may reflect a true absence of top-down control by cod on snow crab. However, in light of the results from Boudreau et al. (2011) and the aforementioned drawbacks of using biomass as an indicator of overall predation pressure, we cannot discount top-down controls of cod on snow crab.

Spawning stock biomass did not show a consistently positive or dome-shaped relationship with recruitment, as we hypothesized. Rather, it was significantly and negatively correlated to subsequent recruitment in 2 areas (EBS, NAFO 3L in the NL ecosystem). This relationship could occur if our data represented the right (declining) limb of a dome-shaped curve. However, that would imply that the spawnerrecruit relationships peak at low spawner biomasses. Also, climate variability and numerous other factors may affect the survival of young crab in the years between fertilization and recruitment. For example, cannibalism may reduce the abundance of recently settled snow crab (Sainte-Marie \& Lafrance 2002) and could perhaps confound or even mimic spawning stock biomass effects, particularly in the EBS and
SGSL regions where the lag time between spawners and recruits was relatively short. In addition, several elements of snow crab reproductive biology may mask any direct link between adult spawning stock biomass and later recruitment. Female snow crab are able to store sperm and to use these reserves to fertilize ova (Elner \& Beninger 1992), so current male or total biomass may not reflect reproductive potential in a given year. In addition, the length of embryonic development (Webb et al. 2007) and the overall reproductive cycle varies and is thought to be influenced by temperature (Kuhn \& Choi 2011) and by whether the female is a primiparous or multiparous spawner (Elner \& Beninger 1992). A crab that remains on a 1 yr reproductive cycle can produce up to twice as many clutches over its reproductive lifetime than a crab on a 2 yr reproductive cycle (Kuhn \& Choi 2011). Therefore, the proportion of crab reproducing on each cycle can have a large impact on a population's overall fecundity. Finally, the geographic distribution of female snow crab may affect reproductive success. For example, in the EBS, female snow crab undergo ontogenetic migrations (Ernst et al. 2005). Parada et al. (2010) used an individual-based model to show that larval retention, and presumably recruitment success, in the EBS varies greatly depending on the location of larval release. They also hypothesize that primiparous females, which aggregate in the middle domain of the EBS, may be the largest source of renewal for the EBS snow crab stock (Parada et al. 2010, Ernst et al. 2012). Hence, we may have failed to detect any relationship between measures of spawning biomass and recruits because spawning biomass is weakly related to total reproductive output.

Another important finding from this study is that the variables we modeled cannot fully explain the observed cycles in recruitment that are characteristic of snow crab and other crab populations. This is evident in the residual patterns for 3 of the regions modeled here (Fig. 4) and is likely to result from internal community dynamics. Such dynamics may be linked to a stronger contribution of primiparous than multiparous females to recruitment (Parada et al. 2010, Ernst et al. 2012) or cannibalism among cohorts within settlement grounds (Sainte-Marie et al. 1996). Alternatively, small-scale changes in climate related to atmospheric circulation like the El Niño could be related to snow crab recruitment cycles (Zheng \& Kruse 2003). Residual cycles could also be related to changes in predation pressures owing to the spatial distribution of snow crab or their predators, as discussed earlier. 


\section{Implications for stock assessment and management}

Reliable stock assessment provides the foundation for successful fisheries management. Stock assessment scientists must make assumptions about recruitment levels to project future snow crab populations, to evaluate the effects of harvesting, and to develop or compare rebuilding plans (NOAA 2001) for depleted stocks. The dominant role of bottom-up climate processes in regulating recruitment and the cyclic patterns we observed in model residuals imply that productivity is not stationary. Incorporating ocean climate effects and population cycles into projections will lead to more reliable predictions of future recruitment that would result in improved management advice. Precautionary reference points, guideline harvest levels, and thresholds for overfishing should be set to reflect variability in production and subsequent recruitment. Further, the current study indicates that warm conditions are linked with poor recruitment. Therefore, if climate change causes bottom conditions to continue to warm, snow crab recruitment will likely decline in our study areas. Studies such as ours, if applied to other important predatory and forage species, can be very important in developing a better basis for ecosystem-based management, especially under a scenario of a changing ocean climate.

Acknowledgements. This study was part of the Ecosystem Studies of Sub-Arctic Seas (ESSAS) program, which provided travel funds for L.A.M. The study was made possible through L.A.M.'s graduate fellowship from the University of Alaska Fairbanks (UAF) Rasmuson Fisheries Research Center and additional funding from the UAF Dr. H. Richard Carlson Scholarship. Partial funding for F.J.M. and L.A.M. was provided by the North Pacific Research Board's Bering Sea Integrated Ecosystem Research Program (BSIERP). We thank D. Chabot, B. Sainte-Marie, and J. Webb for valuable discussions of snow crab early life history. G. Eckert and G. Kruse reviewed and provided helpful comments on an early draft of this paper. Special thanks to all the people who have been involved with design, sampling, and data analyses for research surveys; without their work this project would not be possible. The contribution of F.J.M. to this research was supported by the BEST-BSIERP Bering Sea Project of the North Pacific Research Board (NPRB). This is BEST-BSIERP contribution 73 and NPRB publication 371 .

\section{LITERATURE CITED}

Aydin K, Gaichas S, Ortiz I, Kinzey D, Friday N (2007) A comparison of the Bering Sea, Gulf of Alaska, and Aleutian Islands large marine ecosystems through food web modeling. US Dept Commerce, NOAA Tech Memo NMFS-AFSC-178

Boudreau SA, Anderson SC, Worm B (2011) Top-down interactions and temperature control of snow crab abundance in the northwest Atlantic Ocean. Mar Ecol Prog Ser 429: 169-183

Box GEP, Cox DR (1964) An analysis of transformations. J R Stat Soc B 26:211-252

Burnham KP, Anderson DR (2002) Model selection and multi-model inference: a practical information-theoretic approach. Springer-Verlag, New York, NY

Chabot D, Sainte-Marie B, Briand K, Hanson J (2008) Atlantic cod and snow crab predator-prey size relationship in the Gulf of St. Lawrence, Canada. Mar Ecol Prog Ser 363:227-240

Chassé J, Pettipas RG (2010) Temperature conditions in the southern Gulf of St. Lawrence during 2008 relevant to snow crab. DFO Can Sci Advis Sec 2009/087

Ciannelli L, Dingsor GE, Bogstad B, Ottersen G and others (2007) Spatial anatomy of species survival: effects of predation and climate-driven environmental variability. Ecology 88:635-646

Ciannelli L, Fauchald P, Chan KS, Agostini VN, Dingsør GE (2008) Spatial fisheries ecology: recent progress and future prospects. J Mar Syst 71:223-236

Cury P, Roy C, Mendelssohn R, Bakun A, Husby D, Parrish R (1995) Moderate is better: exploring nonlinear climatic effects on the Californian northern anchovy (Engraulis mordax). In: Beamish R (ed) Climate change and northern fish populations. Can Spec Publ Fish Aquat Sci 121. National Research Council of Canada, Ottawa, p 417-424

Dawe EG, Colbourne EB (2002) Distribution and demography of snow crab (Chionoecetes opilio) males on the Newfoundland and Labrador Shelf. In: Paul AJ, Dawe EG, Elner R, Jamieson GS, Kruse GH, Otto RS, Sainte-Marie B, Shirley TC, Woodby D (eds) Crabs in cold water regions: biology, management, and economics. Alaska Sea Grant Coll Program, AK-SG-02-01, Fairbanks, AK, p 577-594

Dawe EG, Parsons DG, Colbourne EB (2008) Relationships of sea ice extent and bottom water temperature with abundance of snow crab (Chionoecetes opilio) on the Newfoundland-Labrador Shelf. ICES CM Doc 2008/B02

Dawe EG, Koen-Alonso M, Stansbury D, Mullowney D, Chabot D (2012a) Trophic interactions between key predatory fishes and crustaceans: comparison of two Northwest Atlantic systems during a period of ecosystem change. Mar Ecol Prog Ser 469:233-248

> Dawe EG, Mullowney D, Moriyasu M, Wade E (2012b) Effect of temperature on size-at-terminal molt and molting frequency in snow crab Chionoecetes opilio from two Canadian Atlantic ecosystems. Mar Ecol Prog Ser 469: 279-296

DFO (2010) Assessment of snow crab in the southern Gulf of St. Lawrence (Areas 12, 19, 12E, and 12F). DFO Can Sci Advis Sec Sci Advis Rep 2010/015

Dionne M, Sainte-Marie B, Bourget E, Gilbert D (2003) Distribution and habitat selection of early benthic stages of snow crab Chionoecetes opilio. Mar Ecol Prog Ser 259: $117-128$

Elner RW, Beninger PG (1992) The reproductive biology of snow crab, Chionoecetes opilio: a synthesis of recent contributions. Am Zool 32:524-533

Ernst B, Orensanz JM, Armstrong DA (2005) Spatial dynamics of female snow crab (Chionoecetes opilio) in the eastern Bering Sea. Can J Fish Aquat Sci 62:250-268

Ernst B, Armstrong DA, Burgos J, Orensanz JM (2012) Life history schedule and periodic recruitment of female snow crab (Chionoecetes opilio) in the eastern Bering Sea. Can J Fish Aquat Sci 69:532-550 
Foyle TP, O'dor RK, Elner RW (1989) Energetically defining the thermal limits of the snow crab. J Exp Biol 145: 371-393

Frank KT, Petrie B, Choi JS, Leggett WC (2005) Trophic cascades in a formerly cod-dominated ecosystem. Science 308:1621-1623

Hébert M, Wade E, DeGrâce P, Biron M, Hébert A, Moriyasu M (1997) 1996 assessment of snow crab (Chionoecetes opilio) stock in the southern Gulf of St. Lawrence (Areas 12, 18, 19, 25/26 and zones E and F). DFO Can Stock Assoc Res Doc 1997/86

> Hébert M, Benhalima K, Miron G, Moriyasu M (2002) Moulting and growth of male snow crab, Chionoecetes opilio, (O. fabricius, 1788) (Decapoda, Majidae), in the southern Gulf of St. Lawrence. Crustaceana 75:671-702

Hunt GL, Drinkwater K (2007) Introduction to the proceedings of the GLOBEC symposium on effects of climate variability on sub-arctic marine ecosystems. Deep-Sea Res II 54:2453-2455

Kuhn PS, Choi JS (2011) Influence of temperature on embryo developmental cycles and mortality of female Chionoecetes opilio (snow crab) on the Scotian Shelf, Canada. Fish Res 107:245-252

Lilly GR (2008) The decline, recovery, and collapse of Atlantic cod (Gadus morhua) off Labrador and Eastern Newfoundland. In: Kruse GH, Drinkwater K, Ianelli JN, Link JS, Stram DL, Wespestad V, Woodby D (eds) Resiliency of gadid stocks to fishing and climate change. Alaska Sea Grant Coll Program, AK-SG-08-01, Fairbanks, AK, p 67-88

Link JS, Bogstad B, Sparholt H, Lilly GR (2009) Trophic role of Atlantic cod in the ecosystem. Fish Fish 10:58-87

Livingston PA (1989) Interannual trends in Pacific cod, Gadus marcocephalus, predation on three commercially important crab species in the eastern Bering Sea. Fish Bull 87:807-827

Morado JF, Dawe EG, Mullowney DR, Shavey CA and others (2010) Climate change and the worldwide emergence of hematodinium-associated disease: Is there evidence for a relationship? In: Kruse GH, Eckert GL, Foy RJ, Lipcius RN, Sainte-Marie B, Stram DL, Woodby D (eds) Biology and management of exploited crab populations under climate change. Alaska Sea Grant Coll Program, AK-SG-10-01 Fairbanks, AK, p 153-174

Moriyasu M, Lanteigne C (1998) Embryo development and reproductive cycle in the snow crab, Chionoecetes opilio (Crustacea: Majidae), in the southern Gulf of St. Lawrence, Canada. Can J Zool 76:2040-2048

Mullowney DR, Dawe EG, Morado JF, Cawthorn RJ (2011) Sources of variability in prevalence and distribution of bitter crab disease in snow crab (Chionoecetes opilio) along the northeast coast of Newfoundland. ICES J Mar Sci 68:463-471

Murawski SA, Steele JH, Taylor P, Fogarty MJ, Sissenwine MP, Ford M, Suchman C (2010) Why compare marine ecosystems? ICES J Mar Sci 67:1-9

NOAA (2001) Fisheries of the exclusive economic zone off Alaska; rebuilding overfished fisheries. Fed Regist 66: 742-746

NOAA (2011) Extended reconstructed sea surface temperature (ERSST.v3b). Accessed 26 July 2011. www.ncdc. noaa.gov/ersst/

Orensanz JL, Ernst B, Armstrong DA, Stabeno P, Livingston P (2004) Contraction of the geographic range of distribution of snow crab (Chionoecetes opilio) in the eastern Bering
Sea: an environmental ratchet. CalCOFI Rep 45:65-79

Orensanz JM, Ernst B, Armstrong DA (2007) Variation of female size and state at maturity in snow crab (Chinoecetes opilio) (Brachyura: Majidae) from the eastern Bering Sea. J Crustac Biol 27:576-591

Parada C, Armstrong DA, Ernst B, Hinckley S, Orensanz JM (2010) Spatial dynamics of snow crab (Chionoecetes opilio) in the eastern Bering Sea - putting together the pieces of the puzzle. Bull Mar Sci 86:413-437

R Development Core Team (2011) R: A language and environment for statistical computing. www.R-project.org

Ruppert JLW, Fortin MJ, Rose GA, Devillers R (2010) Environmental mediation of Atlantic cod on fish community composition: an application of multivariate regression tree analysis to exploited marine ecosystems. Mar Ecol Prog Ser 411:189-201

> Sainte-Marie B, Lafrance M (2002) Growth and survival of recently settled snow crab Chionoecetes opilio in relation to intra- and intercohort competition and cannibalism: a laboratory study. Mar Ecol Prog Ser 244:191-203

Sainte-Marie B, Raymond S, Brêthes JC (1995) Growth and maturation of the benthic stages of male snow crab, Chionoecetes opilio (Brachyura: Majidae). Can J Fish Aquat Sci 52:903-924

Sainte-Marie B, Sévigny JM, Smith BD, Lovrich GA (1996) Recruitment variability in snow crab (Chionoecetes opilio): pattern, possible causes, and implications for fishery management. In: Baxter B (ed) High latitude crabs: biology, management, and economics. Alaska Sea Grant Coll Program, AK SG 96-02, Fairbanks, AK, p 451-477

Sainte-Marie B, Gosselin T, Sévigny JM, Urbani N (2008) The snow crab mating system: opportunity for natural and unnatural selection in a changing environment. Bull Mar Sci 83:131-161

Smith TM, Reynolds RW, Peterson TC, Lawrimore J (2008) Improvements to NOAA's historical merged land-ocean surface temperature analysis (1880-2006). J Clim 21: 2283-2296

Swain DP, Savoie L, Hurlbut T, Surette T, Daigle D (2009) Assessment of the southern Gulf of St. Lawrence cod stock, February 2009. DFO Can Sci Advis Sec Res Doc 2009/037

Thompson GG, Ianelli JN, Lauth RR (2010) Assessment of the Pacific cod stock in the eastern Bering Sea and Aleutian Islands area. In: Stock assessment and fishery evaluation report for the groundfish resources of the Bering Sea/Aleutian Islands regions. North Pacific Fishery Management Council, Anchorage, AK, p 243-424

Turnock BJ, Rugolo LJ (2010) Stock assessment of eastern Bering Sea snow crab. In: Stock assessment and fishery evaluation report for the king and Tanner crab fisheries of the Bering Sea and Aleutian Islands regions. North Pacific Fishery Management Council, Anchorage, AK, p 33-124

> Webb JB, Eckert GL, Shirley TC, Tamone SL (2007) Changes in embryonic development and hatching in Chionoecetes opilio (snow crab) with variation in incubation temperature. Biol Bull 213:67-75

Windle MJS, Rose GA, Devillers R, Fortin MJ (2012) Spatiotemporal variations of invertebrate-cod-temperature relationships on the Newfoundland Shelf, 1995-2009. Mar Ecol Prog Ser 469:263-278

> Zheng J, Kruse GH (2003) Stock-recruitment relationships for three major Alaskan crab stocks. Fish Res 65:103-121

Zheng J, Kruse GH (2006) Recruitment variation of eastern Bering Sea crabs: Climate-forcing or top-down effects? Prog Oceanogr 68:184-204 